\title{
Adenovirus Antigen Measurement
}

National Cancer Institute

\section{Source}

National Cancer Institute. Adenovirus Antigen Measurement. NCI Thesaurus. Code C154830.

The determination of the adenovirus antigen present in a sample. 